\title{
Discarding Armature and Barrel Optimization for a Cannon Caliber Electromagnetic Launcher System
}

\author{
Center for Electromechanics \\ The University of Texas at Austin \\ BRC, Mail Code 77000 \\ Austin, TX 78712
}

J. H. Price, H. D. Yun, J. P. Kajs, J. R. Kitzmiller, S. B. Pratap, and M. D. Werst

\begin{abstract}
This publication details the optimization and baseline design of the discarding metal armature and electromagnetic railgun developed for the U.S. Army Armament Research Development and Engineering Center and U.S. Marine Corps sponsored Cannon Caliber Electromagnetic Launcher program. The primary goals of this program have been to defeat specified targets at 1,500 and $3,000 \mathrm{~m}$ range utilizing an electromagnetic launcher system weighing less than $\mathbf{5 , 0 0 0} \mathrm{lb}$.
\end{abstract}

An optimization algorithm was developed to integrate the armor-penetrating sub-projectile with a discarding armaturedsabot forming an integrated launch package. This algorithm coupled integrated launch package electromagnetic and structural design requirements to launcher design parameters incluting rail resistance per unit length and inductance per unit length as a function of launcher rail geometric and structural configurations. Pulsed power supply size and mass requirements were subsequently estimated from launcher performance predictions.

This study shows that minimizing breech energy required by the launcher will minimize total system mass. A two-turn augmented, rectangular bore barrel, firing a mid-drive discarding armature that launches its subprojectile at $1,850 \mathrm{~m} / \mathrm{s}$ resulted in minimum system mass. The series augmented electromagnetic launcher will be powered by a 4-pole, air-core, compulsator that stores the total launch energy inertially in its composite rotor. This compulsator driven electromagnetic test bed will be capable of accelerating 15 each, $185 \mathrm{~g}$ integrated launch packages in three salvos of five shots, with a shot rate of 300 rounds per minute and two seconds between salvos.

\section{INTRODUCTION}

The Center for Electromechanics at The University of Texas (CEM-UT), under subcontract to FMC Corporation Naval Systems Division (FMC-NSD) and in cooperation with Kaman Sciences Corporation (KSC) on the CannonCaliber Electromagnetic Launcher (CCEML) program, performed a detailed analytical trade study of the performance domain for a number of discarding armature and barrel configurations sized to launch a set of functional subprojectile designs capable of defeating program target requirements [1], [2], [3]. Fig. 1 illustrates the integrated launch package (ILP) and baseline railgun cross section resulting from this study. The following sections describe the approach used in their design optimization.

\section{EXCaliber Optimization Algorithm}

Development of a general projectile, armature and barrel design algorithm was required for this effort. An algorithm based on the approach used by Zielinski [4] was ultimately developed and implemented in system trade studies. This

Manuscript received April 20, 1994.

This work was supporied by U.S. Aimy ARDEC under contract number DAAA21-92-C-0060. algorithm builds on Zielinski's approach by including additional detail in defining armature and barrel structural/thermal design requirements to study variations of launch environment conditions and the resultant impact on power supply size and mass.

The algorithm to perform the launch package and barrel design trade-study was named EXCaliber (Electromagnetic eXperimental Caliber) and was jointly developed under the CCEML and SLEKE programs [5]. Governing armature and barrel design equations were coded into a FORTRAN program structure directly linked to a high-frequency, twodimensional electromagnetic modeling routine based on Leuer's method [6] so that barrel inductance gradient and rail repulsion loads could be directly estimated for each barrel design generated by the optimization process. Thermal and structural design constraints for both the armature and barrel were interdependently modeled. Evroliber iterates upon a design to minimize armature and barrel mass as well as minimize required gun breech energy demands.

To explore the performance domain, KSC generated a set of functional projectile designs (Table I) that would each defeat the targets at range while minimizing subprojectile muzzle kinetic energy. Each projectile in the set was designed to be launched at a fixed muzzle velocity. The launch velocity range studied was between 1.7 and $2.3 \mathrm{~km} / \mathrm{s}$
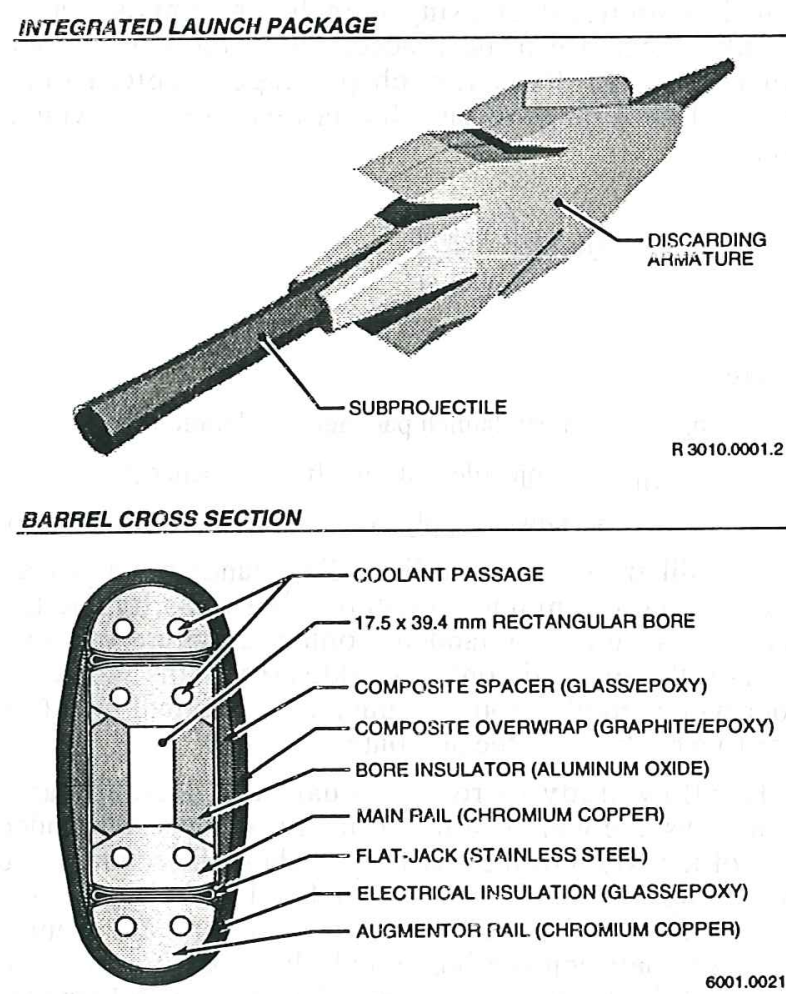

Fig. 1. Integrated launch package and barrel cross section 
Table I. Subprojectile and discarding armature masses and energies

\begin{tabular}{|c|c|c|c|c|c|}
\hline Nose Tip Radius & $0.1^{\prime \prime}$ & & & & \\
\hline Launch Velocity [km/s] & 1.70 & 1.85 & 2.00 & 2.15 & 2.30 \\
\hline \multirow[t]{5}{*}{ Rod Diameter [mm] } & 8.00 & 7.11 & 6.81 & 6.35 & 6.17 \\
\hline & \multicolumn{5}{|c|}{ Subprojectile Mass [kg] } \\
\hline & 0.146802 & 0.109737 & 0.094865 & 0.079735 & 0.072302 \\
\hline & \multicolumn{5}{|c|}{ Subprojectile Muzzle Energy [J] } \\
\hline & 212,129 & 187,787 & 189,731 & 184,287 & 191,238 \\
\hline Launch Time [ms] & \multicolumn{5}{|c|}{2 Turn Rect. Discarding Armature/Sabot Mass [kg] } \\
\hline $\begin{array}{l}1.4 \\
1.7 \\
2.0 \\
2.3 \\
2.6 \\
2.9\end{array}$ & $\begin{array}{l}0.0932 \\
0.0750 \\
0.0661 \\
0.0613 \\
0.0586 \\
0.0571 \\
\end{array}$ & $\begin{array}{l}0.0805 \\
0.0656 \\
0.0585 \\
0.0513 \\
0.0485 \\
0.0466\end{array}$ & $\begin{array}{l}0.0763 \\
0.0635 \\
0.0545 \\
0.0501 \\
0.0474 \\
0.0455\end{array}$ & $\begin{array}{l}0.0729 \\
0.0611 \\
0.0524 \\
0.0482 \\
0.0456 \\
0.0438\end{array}$ & $\begin{array}{l}0.0730 \\
0.0597 \\
0.0526 \\
0.0485 \\
0.0460 \\
0.0442\end{array}$ \\
\hline Launch Time [ms] & \multicolumn{5}{|c|}{2 Turn Rect. Launch Package Muzzle Energy [J] } \\
\hline $\begin{array}{l}1.4 \\
1.7 \\
2.0 \\
2.3 \\
2.6 \\
2.9\end{array}$ & $\begin{array}{l}346,803 \\
320,504 \\
307,643 \\
300,707 \\
296,806 \\
294,638\end{array}$ & $\begin{array}{l}325,542 \\
300,045 \\
287,895 \\
275,574 \\
270,782 \\
267,531\end{array}$ & $\begin{array}{l}342,331 \\
316,731 \\
298,731 \\
289,931 \\
284,531 \\
280,731\end{array}$ & $\begin{array}{l}352,777 \\
325,504 \\
305,396 \\
295,689 \\
289,680 \\
285,519\end{array}$ & $\begin{array}{l}384,323 \\
349,144 \\
330,365 \\
319,520 \\
312,908 \\
308,147\end{array}$ \\
\hline
\end{tabular}

(for the iteration presented here). A discarding armature/sabot and barrel was sized for each subprojectile design. Launcher and armature design parameters studied included round, square and rectangular gun bore geometrys, one-turn (simple), two and three-turn (augmented) barrel rail configurations, and launch times between 1.4 and $2.9 \mathrm{~ms}$. Four limits that drove the design of the discarding armature were subprojectile mass, diameter, launch time, and launch velocity.

In addition, power supply mass was found to be a strong function of the pulse width of the current wave form required to drive the launch package because pulse width from the power supply is equivalent to the launch time of the ILP. Launch time is critical to launch package design; given a launch velocity, decreasing launch time imposes a corresponding increase in peak acceleration the launch package must survive. Peak launch package acceleration was obtained for a range of launch times with the following relation:

$$
a_{\text {peak }}=\operatorname{PAAR}\left(\frac{v_{\text {rod }}}{t_{\text {exit }}}\right)
$$

where

$$
\begin{aligned}
\mathrm{a}_{\text {peak }} & \equiv \text { peak launch package acceleration }\left(\mathrm{m} / \mathrm{s}^{2}\right) \\
\mathrm{t}_{\text {exit }} & \equiv \text { projectile exit time from launcher }(\mathrm{s}) \\
\text { PAAR } & \equiv \text { power supply peak/average acceleration ratio }
\end{aligned}
$$

EXCaliber employed a discarding, tandem contact armature to obtain minimum armature/sabot mass for the launch event constraints. A tandem contact armature was chosen because the forward contact could serve as the forward bore rider while simultaneously reducing the thermal load (due to resistive heating) on the aft contact.

To allow study of round, square and rectangular bore geometrys, the widths of the armature contacts were independent of the width of the rear ramp (sabot tail section). A bore aspect angle called Gamma was defined as the common parameter among the three bore geometrys (fig. 2). Gamma is the angle between the horizontal plane passing through the center of the bore insulators and the axial seam between the bore insulators and rails. Gamma was varied between $45^{\circ}$ and a maximum value where the contact width ( $x_{\text {bore }}$ ) was equal to the ramp width $\left(\mathrm{x}_{\mathrm{ramp}}=\mathrm{y}_{\text {ramp }}\right)$. The square bore geometry, a simple case of the rectangular bore geometry, was defined by Gammas equal to $45^{\circ}$. Round bore geometrys were modeled by including additional armature mass to account for transverse bore riders for lateral stability and cusp-shaped cylindrical contacts with the rails. The height of the bore riders was set equal to the ramp height $\left(y_{\text {ramp }}\right)$ and axial length equal to the total axial length of both armature contacts $\left(z_{3}+z_{4}\right)$.

A "side-by-side" primary and augmenting rail geometry (fig. 3) was modeled in the trade studies. The side-by-side geometry was selected because of closer agreement between three-dimensional (3-D) electromagnetic (EM) finite element analysis (FEA) models and high-frequency models of the driving inductance gradient and advantages gained in structural design of the launcher [7]. Throughout the launch package and launcher trade-study process, 3-D electromagnetic finite element analysis of the launch package and launcher were performed and used to calibrate design assumptions of the EXCaliber algorithm. Three-dimensional EM FEA models of augmented launchers included field/current diffusion effects and predicted a lower driving inductance gradient than that predicted with the high frequency method. This discrepancy was identified prior to the initiation of this effort and influenced our recommendations regarding an augmented launcher design approach. As a result, two augmenting rail configurations were evaluated in the trade-study and conceptual design efforts: "side-by-side" and "back-to-back" (fig. 4). EXCaliber used the side-by-side configuration in the launcher optimization process to calculate driving inductance gradient and size armature mass. Although EXCaliber's prediction of driving inductance gradient was known to be somewhat higher than 3-D EM FEA models, the back-to-back configuration was considered to be a fall-back option because it provided a higher net driving inductance gradient than the back-to-back geometry (for the same total rail cross-sectional area) and could be used in the event that the side-by-side driving inductance gradient was inadequate.

Rail resistive heating energy loss was initially estimated assuming $70 \%$ of the total gun current was distributed in the skin depth of the horizontal inner surfaces of the conductors and the remaining current distributed in the back surfaces of the conductors. However, this approach was found to be 


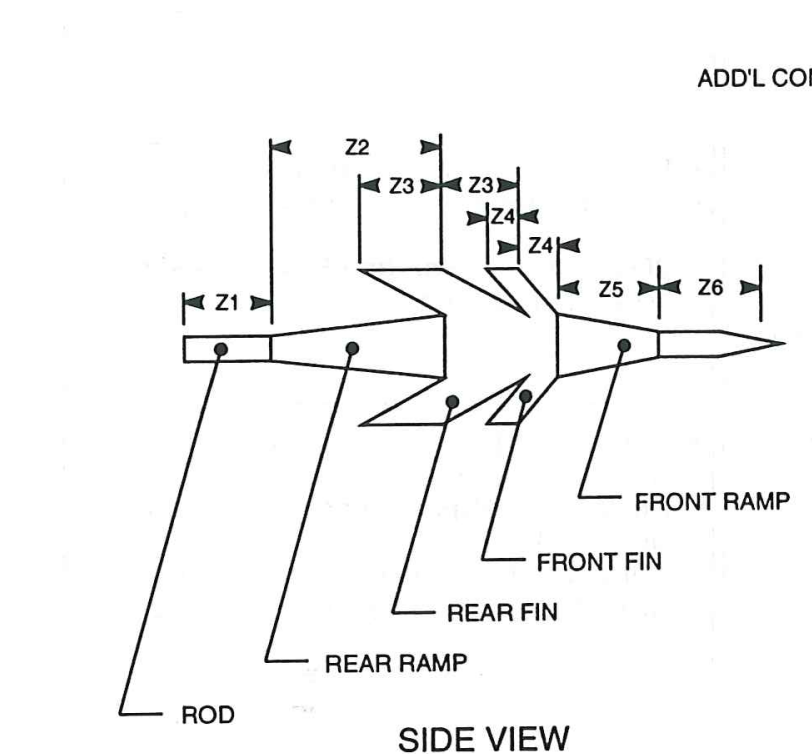

BORE RIDER FOR ROUND BORE
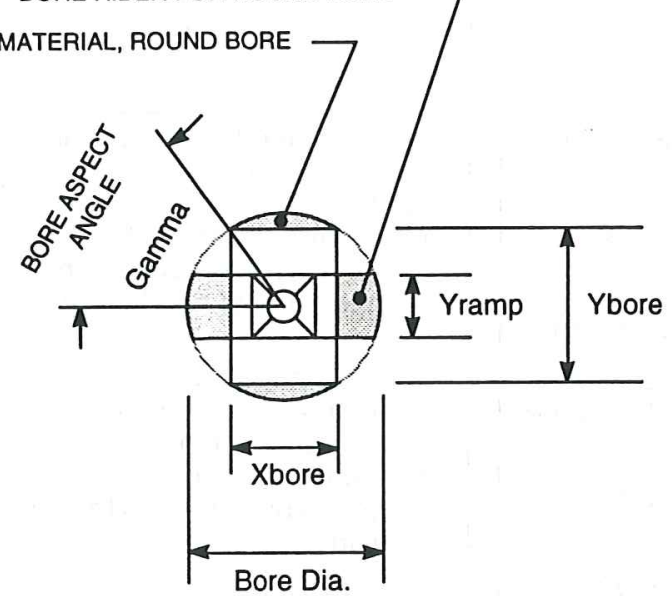

AXIAL VIEW

Fig. 2. Armature geometry definition

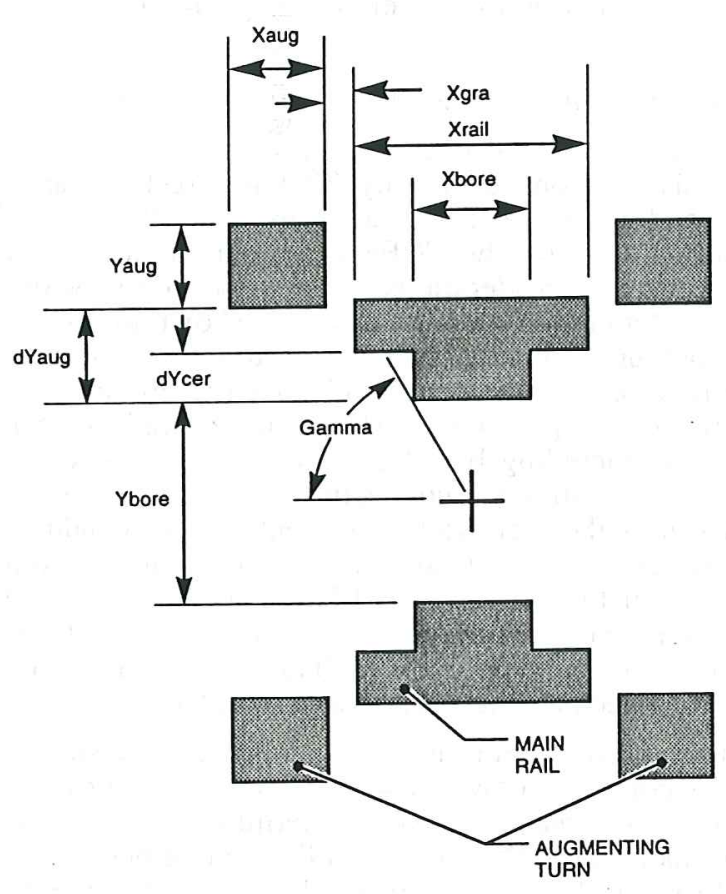

6001.0023

Fig. 3. Side-by-side rail geometry parameters

inadequate for providing insight to the sensitivity of rail heating due to geometric variation of the rail cross section. The rail and augmenting turn resistivity and heat deposition model was subsequently improved to account for timedependent current diffusion (one-dimensional) in the conductors as a function of the rail surface current distribution as predicted by the high-frequency model. Conductor area was sized to limit bulk temperature rise in the rails to $17^{\circ} \mathrm{C}$ per shot $\left(100^{\circ} \mathrm{C}\right.$ total for a six-shot salvo). Rail sizing also included provisions for cooling passages to allow active cooling of the rails during and between salvos.

EXCaliber estimated launcher performance and structural requirements in concert with launch package design require- ments. Besides varying the bore aspect angle Gamma, the width and height of the ceramic bore insulators as well as the spacing of the augmenting turn conductors were varied to study the effect of these variations on breech energy requirements and launcher mass. Barrel structural parameters included calculation of rail repulsion loads used to size the rail support composite overwrap members and determine the spacing between the primary rails and augmenting turns $\left(\mathrm{x}_{\mathrm{gra}}\right)$, calculate bore deflections under peak load (bore strann), and estimate launcher mass. To fully define total launch package mass and provide adequate rail cross-sectional area to limit rail resistive heating to acceptable levels, iteration of this algorithm was required, as the armature heating is a function of the launcher inductance gradient and conversely, the launcher inductance gradient is a function of the launch package mass.

Upon convergence of the iterative solution for a specific case, launch package and launcher designs comprised a matched system with a minimum breech energy requirement and minimum mass. Performance results of each case studied were then used as inputs to power supply design optimization efforts.

\section{Launch Package and Launcher Trade-Study Results}

Design parameter variations explored in the final trade studies included:

- Five subprojectile designs optimized by KSC to achieve contract penetration requirements, with corresponding launch muzzle velocities of $1.70,1.85,2.00,2.15$ and $2.30 \mathrm{~km} / \mathrm{s}$,

- six launch times of $1.4,1.7,2.0,2.3,2.6$, and $2.9 \mathrm{~ms}$,

- round, square and rectangular bore geometrys

- five bore aspect angles between square and maximum rectangular,

- one (simple railgun), two, and three-turn (augmented railgun) rail configurations,

- and bore insulator thicknesses of $0.25,0.5$, and 0.75 in.

Optimum performance of the launch package and launcher trade studies is best summarized by comparing the breech 

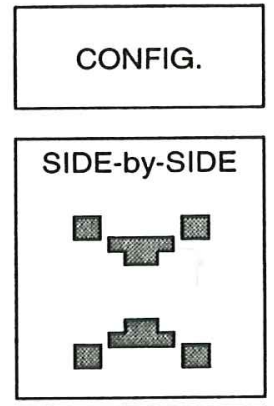

BACK-to-BACK

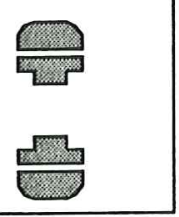

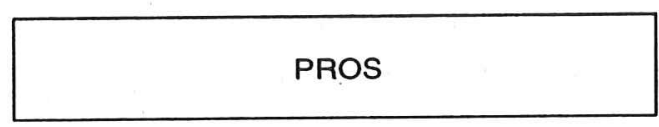

- Allows control of augmenting turn field diffusion into main rail

- Reduces EM load on main rail/flatjack

- Good current distribution (low peak temperature) in augmenting turn

- Simple augmenting turn muzzle crossover

- 3D L' 0-5\% higher than EXCaliber sideby-side prediction

- Minimum barrel mass

- Requires one composite overwrap structure

\section{CONS}

- Increases barrel mass requirements

- Requires three composite overwrap structures

- 3D L' $5-10 \%$ lower than EXCaliber sideby-side prediction

- Requires separate augmenting turn muzzle crossover

- EM load on flatjack higher (requires higher pressure)

- Current distribution in augmenting turn not as uniform as side-by-side

Fig. 4. Side-by-side vs. back-to-back augmenting rail configuration issues

energy requirements of the different launcher configurations and launch velocities studied. Fig. 5 ranks the launcher types in terms of minimum breech energy as a function of launch velocity. Several significant conclusions are evident from this comparison:

- Minimum breech energy demand for all launchers studied occurred at $1.85 \mathrm{~km} / \mathrm{s}$ launch velocity. This was primarily due to the effects of increasing subprojectile muzzle energy as launch velocity was increased and higher energy dissipation in the armature voltage drop due to assumed contact voltage transition at velocities above 1 $\mathrm{km} / \mathrm{s}$.

- At all launch velocities, the two-turn augmented rectangular bore launcher required the minimum breech energy of all launchers studied.

- One-, two-, and three-turn round bore guns demand higher breech energy than either square or rectangular one, two and three-turn launchers. This result was partly due to the additional borerider and contact mass required in the round bore cases.

- As launch velocity was increased, breech energy demand of one-turn (simple rail) configurations increased at a higher rate than two- and three-turn (augmented) configurations. In the one-turn launchers, armature mass increased dramatically with velocity to accommodate the correspondingly higher action the armature must manage.

- In all cases, the one-turn launchers yielded the highest launch package efficiencies (launch package kinetic energy (KE) divided by breech energy); however, the two-turn rectangular bore launchers required less breech energy to launch the same projectiles therefore providing the highest subprojectile efficiencies (subprojectile $\mathrm{KE}$ divided by breech energy). This is a very important conclusion in that subprojectile $\mathrm{KE}$ at a given velocity is more representative of terminal performance of the projectile than muzzle KE of the launch package when compared to breech energy demand. Therefore, subprojectile efficiency is a more useful figure of merit to judge launcher performance than launch package muzzle energy.

As a result of these studies a two-turn, rectangular bore launcher firing an ILP launched at a muzzle velocity of 1.85 $\mathrm{km} / \mathrm{s}$ was selected as the baseline design for the CCEML system.

\section{Discarding Armature and Launcher Baseline Design}

Based on the trade studies and subsequent detail design and analysis iterations, a 17.5 by $39.4 \mathrm{~mm}$ rectangular bore launcher and $85 \mathrm{~g}$ discarding armature was selected as the final configuration for the CCEML system due to minimum mass and energy considerations. A cross-section view of the launcher and armature baseline design is shown in fig. 1. A $0.5 \mathrm{~m}$ mock-up of this design was constructed to assess fabrication requirements as well as electromagnetic and structural performance [8]. Fig. 6 shows an assembly layout of this launcher including barrel subassembly, breech connection and muzzle crossover connection. The barrel subassembly consists of the main rails, augmenting turn conductors, flat jacks, ceramic bore insulators, electrical insulation and composite structural overwrap. Electrical connection to the ends of main rails and augmenting turns is made at crossdrilled cylindrical receptacles. The breech and muzzle crossover connectors "plug" into these receptacles[9].

The breech connection assembly concept is illustrated in fig. 7 and consists of two symmetric subassemblies which plug into the receptacles in the rail terminals. Cross-drilled holes are included in the subassemblies so that once connection with the rails is made, through-bolts may be used to clamp the subassemblies to each other and provide attachment for the recoil system. Breech connection subassemblies also serve as an integral flexible cable termination[9]. All conductors within the breech connection were designed to limit resistive heating thermal rise to acceptable levels over 15 shots without the requirement for active cooling.

\section{CONCLUSIONS AND RECOMMENDATIONS}

This study determined that a series augmented, rectangular bore launcher and a mid-drive, two-piece armature/sabot integrated launch package results in the lightest mass EM gun system for CCEML. Significant conclusions drawn from this work can be summarized as follows:

1) A two-turn series augmented launcher provides better subprojectile kinetic energy efficiency than a simple railgun due to the reduced armature mass required in the ILP. 


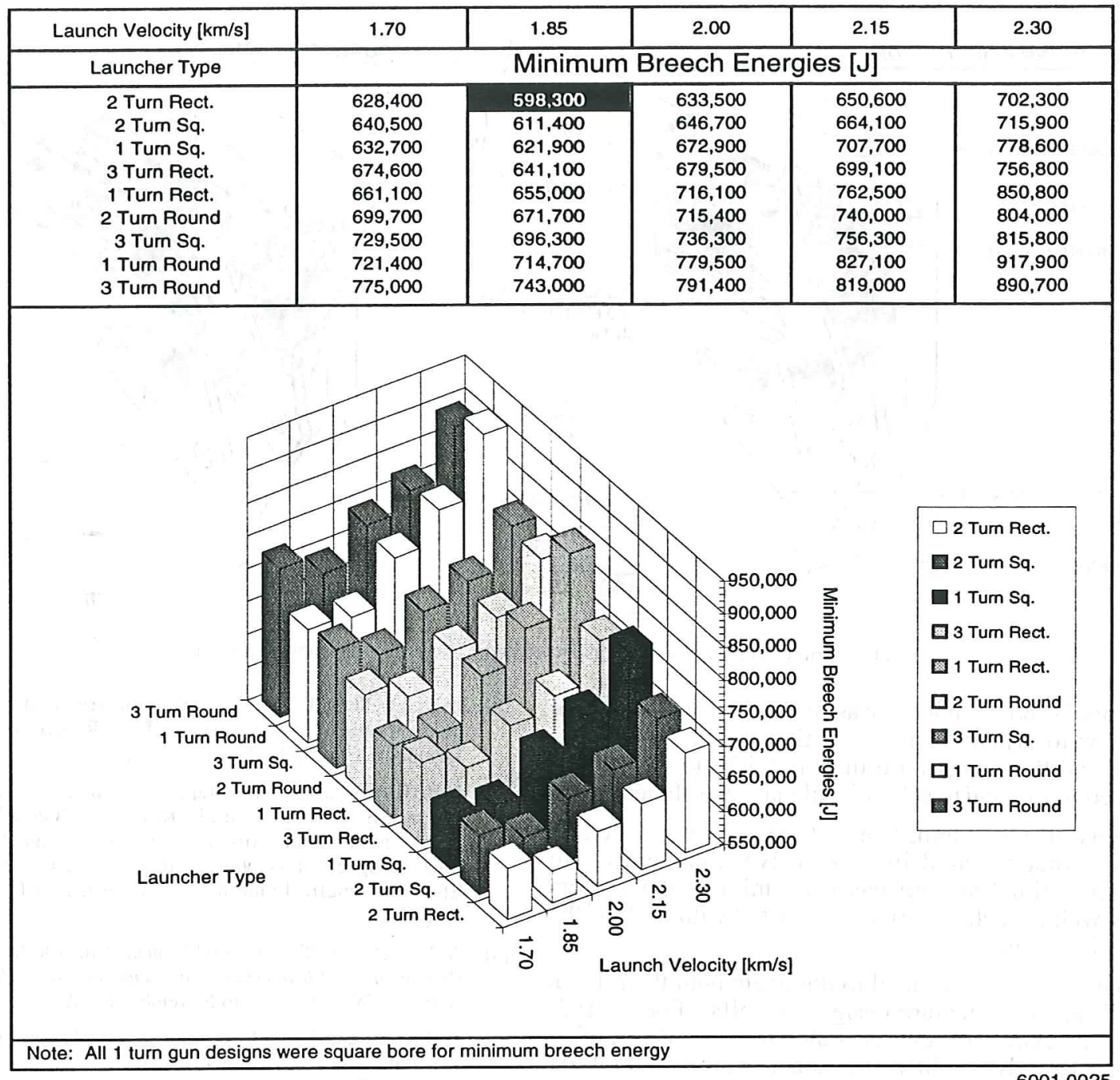

Fig. 5. Trade study results. Optimum design corresponds to minimum breech energy required

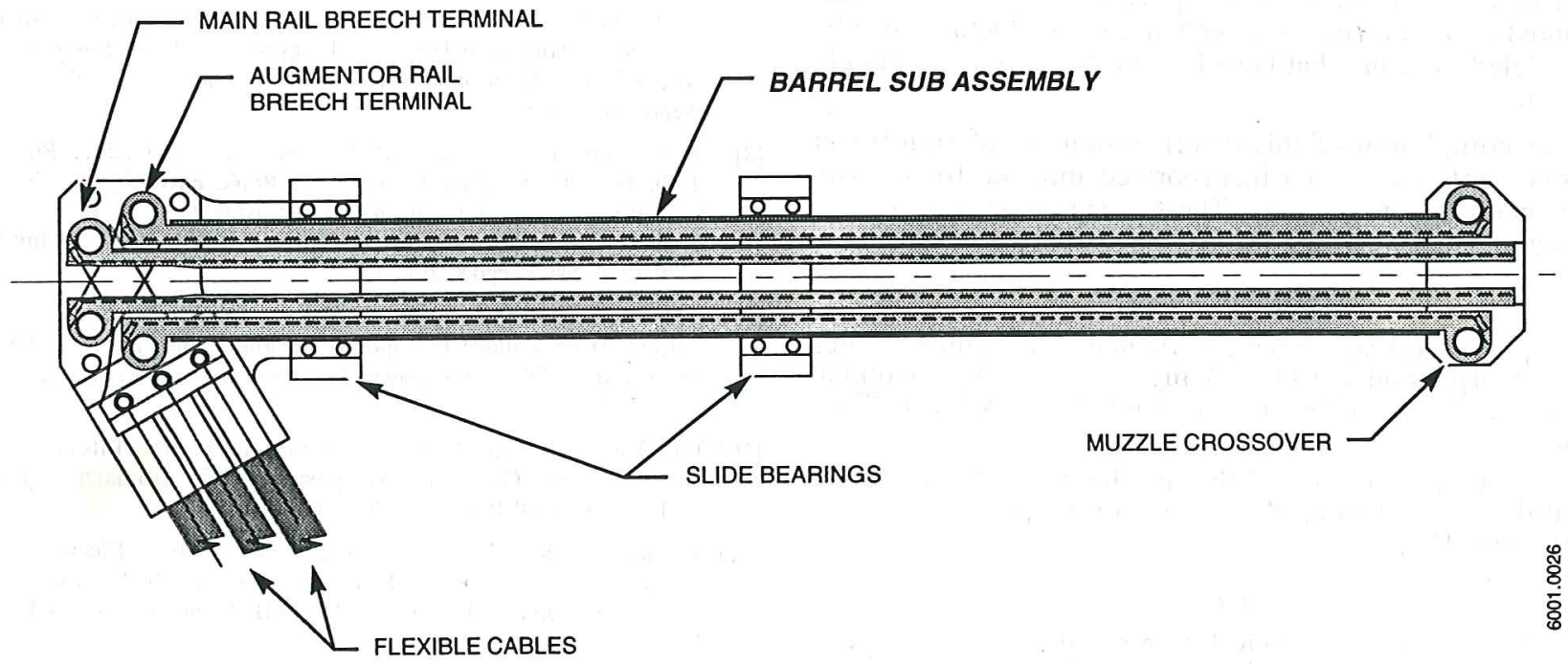

Fig. 6. Barrel layout 

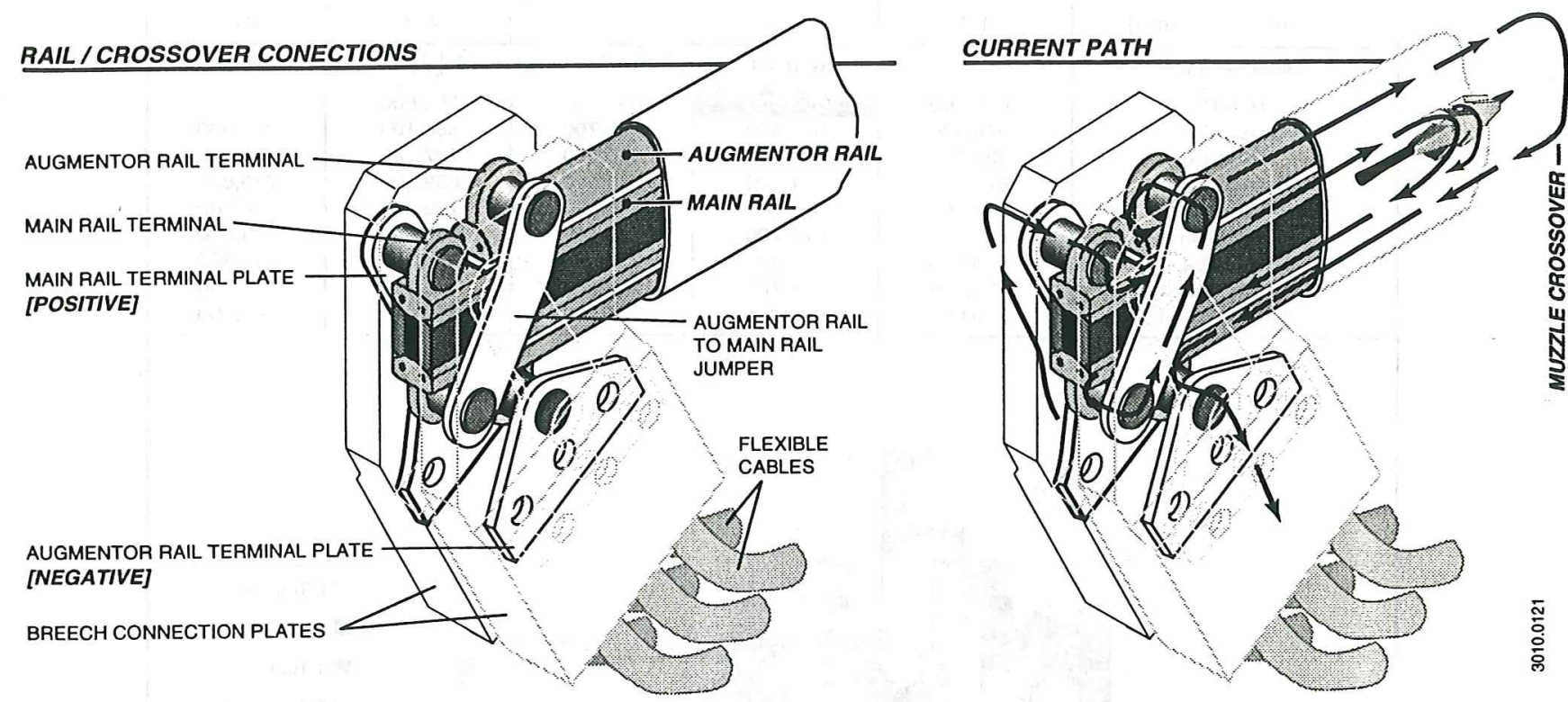

Fig. 7. Breech connection assembly (symmetric conductors not shown for clarity)

2) A rectangular bore launcher was found to provide a higher penetrator to armature mass fraction than a round-bore railgun, and the aspect ratio of bore width to height was optimized to maximize subprojectile launch efficiency.

3) Variations of gun length, launch time and peak acceleration were incorporated into extensive trade studies to select an optimal system based on minimizing system mass as well as technical risks associated with each of the major subsystems.

4) Thermal considerations tend to dominate both the railgun rail and the ILP armature design tradeoffs. For the railgun rails, resistive heating is compounded as the number of shots per salvo is increased since there is very little time to cool between shots.

5) Current diffusion effects on the driving inductance gradient in the augmented launchers of interest were analytically characterized in great detail and were found to strongly influence power supply design. Two-dimensional current diffusion effects in rail conductors must be modeled to insure that launcher performance is accurately predicted.

Since completion of this effort, a number of significant improvements have been incorporated into the final barrel and launch package designs. These design modifications are covered in detail by Werst [8] and Hayden [10].

\section{ACKNOWLEDGMENT}

This program is supported and funded by the United States Marine Corps, and the U.S. Army ARDEC Close Combat Armaments Center under Contract number DAAA21-92-C0060 .

This work was performed during Phase I for the program. For further information, please refer to the program Phase I Final Report [11].

\section{REFERENCES}

[1] K. A. Jamison, "A Technical Assessment Of Electromagnetic Propulsion For Small Caliber Weapons Applications," Ballistic Research Laboratory, Aberdeen Proving Ground, Maryland, Technical Report BRL-TR-3170, November 1990.
[2] Lindsey Thornhill, et al, "Design Study of a Cannon Caliber Electromagnetic Launch System," Final Report to Air Fire Armament Laboratory from SAIC, February 1991.

[3] J. R. Kitzmiller, S. B. Pratap, T. A. Aanstoos, K. G. Cook, R. A. Kuenast, B. T. Murphy, and D. R. Perkins, "Optimization and Critical Design Issues of the Air-Core Compulsator for the Cannon Caliber Electromagnetic Launcher System (CCEML)," 7th Symposium on Electromagnetic Launch Technology, April 1994, San Diego. California.

[4] A. E. Zielinski, "Saboted Rod Projectile for Electromagnetic Launch," Proceedings, 12th International Symposium on Ballistics, Vol. II, San Antonio, TX, October 30 to November 1, 1990.

[5] J. H. Price and H. D. Yun, "Design and Testing of Integrated Metal Armature Sabots for Launch of Armor Penetrating Projectiles From Electric Guns," 7th Symposium on Electromagnetic Launch Technology, April 1994, San Diego, California.

[6] J.A. Leuer, "Electromagnetic Modeling of Complex Railgun Geometries," IEEE Transactions Magnetics, Vol. Mag-22, No. 6, , pp. 1584-1590, November 1986.

[7] H. D. Yun and J. H. Price, "Electromagnetic And Structural Analysis Of Electric Gun And Integrated Launch Package Systems," 7th Symposium on Electromagnetic Launch Technology, April 1994, San Diego, California.

[8] M. D. Werst, K. G. Cook, J. R. Kitzmiller, H.-P. Liu, J. H. Price, and H. D. Yun, "Design And Testing Of A Rapid Fire, Lightweight, Ultra Stiff Railgun For A Cannon Caliber Electromagnetic Launcher System," 7th Symposium on Electromagnetic Launch Technology. April 1994, San Diego California

[9] J. H. Price, D. A. Badger, and R. A. Lee, "Design and Testing of High Current, High Voltage Hexapolar Flexible Cables for Pulsed Power Applications," 8th Pulsed Power Conference, San Diego, CA, June 17 to 19,1991 .

[10] T.E. Hayden, et al, "Effective Launch Package Integration for Electromagnetic Guns," 7th Symposium on Electromagnetic Launch Technology, April 1994, San Diego California.

[11] Scientific Technical Report for the Cannon Caliber Electromagnetic Launcher (CCEML), Phase I Final Report, Vol. II, Section 5, under contract no. DAAA21-92-C-0060, CDRL Sequence No. A011, May 1993. 